\title{
Assessment of Genetic Diversity in Contrasting Sugarcane Varieties Using Inter-Simple Sequence Repeat (ISSR) Markers
}

\author{
Maria Lucilia M. da Costa ${ }^{1}$, Lidiane L. Barbosa Amorim², Alberto V. C. Onofre ${ }^{2}$, Luiz J. O. Tavares de \\ Melo $^{3}$, Maria Betânia M. de Oliveira ${ }^{2}$, Reginaldo de Carvalho', Ana M. Benko-Iseppon ${ }^{2 \#}$ \\ ${ }^{1}$ Universidade Federal Rural de Pernambuco (UFRPE), Genetics Department, Recife, Brazil; ${ }^{2}$ Universidade Federal de Pernambuco \\ (UFPE), Genetics Department, Laboratory of Plant Genetics and Biotechnology, Recife, Brazil; ${ }^{3}$ Estação Experimental de Cana-de- \\ Açúcar do Carpina (EECAC/UFRPE), Carpina, Brazil. \\ Email: " ana.benko.iseppon@pq.cnpq.br
}

Received May $23^{\text {rd }}, 2011$; revised June $29^{\text {th }}, 2011$; accepted July $15^{\text {th }}, 2011$.

\begin{abstract}
Sugarcane is an important tropical crop, responsible for two thirds of the world sugar production, gaining actually importance as a source of biofuel. Drought tolerance is a very important feature considering the actual climate change scenario throughout the world. This study aimed to determine the genetic diversity between sugarcane varieties with contrasting features under drought. For this purpose, twelve ISSR primers were used to characterize nine sugarcane varieties under cultivation in different countries including selected drought resistant material from Northeast Brazil and two varieties from India as contrasting genotypes. 317 scorable bands were generated, among which 301 comprised polymorphic markers, with an average of 25 polymorphic bands per primer. In the generated dendrogram the accessions were placed in clusters, where cluster A included two varieties from India (Co331 and Co419), and B comprised plants eight Brazilian accessions and a "Barbado" variety. Within this clade, drought tolerant and susceptible varieties were clearly separated. The present evaluation revealed important contrasting parental candidates regarding their drought response, very promising for future mapping approaches aiming the identification of quantitative trait loci (QTLs) associated to drought in sugarcane. The selected primers were used for the first time in sugarcane, representing valuable tools for future evaluations, with emphasis to diversity characterization and genetic mapping.
\end{abstract}

Keywords: Saccharum, Genetic Variability, ISSR Marker, Drought Tolerance

\section{Introduction}

Sugarcane is among the most important industrial crops of tropical and subtropical regions and is cultivated in more than 90 countries around the globe primarily for its ability to store high concentrations of sugar and more recently for the production of ethanol, very demanded as biofuel. Modern sugarcane are complex hybrids derived largely from the interspecific crosses involving Saccharum officinarum L. $(2 n=80)$ and the wild species $S$. spontaneum L. $(2 n=40$ - 128) [1].

The choice of the variety is one of the most important factors in sugarcane breeding and production. Different varieties have different yield potentials, pest and disease resistance and are bred for different ecological and eco-

${ }^{*}$ CNPq Conselho Nacional de Desenvolvimento Científico e Tecnológico, Brazil nomic conditions [2-4]. Therefore, the establishment of the adequate variety to be grown in a given region, characterized by water deficiency originated by irregular distribution of rainfall, is of paramount importance.

Molecular markers are powerful tools to uncover the complex genetics of sugarcane and to assist breeders in genetic improvement of varieties [5-7]. The employment of new technologies to help in the association of traits with genetic markers and genetic maps can aid in achieving further yield increases in breeding programs [8-10].

Information regarding genetic variability may contribute to germplasm conservation and use, such as by identifying duplicates in databanks, in monitoring the genetic integrity of accessions, and by providing additional information that may help in the establishment of relationships among genotypes. Traditionally, the choice of pa- 
rental lines in sugarcane breeding programs has been defined on the basis of agronomic characters and pedigree records, using bi-parental crosses or polycrosses between elite genotypes. However, the lack of genealogy data and the inadequate identification of some genotypes have impaired an accurate estimation of the genetic diversity (GD) among sugarcane accessions based on pedigree data. In addition, the continuous selection for the same traits such as sucrose content in breeding programs has caused a reduction in GD, limiting further advances in sugarcane breeding [11].

Several different molecular markers have been used in previous studies that have examined diversity among sugarcane cultivars from different regions worldwide. These include RFLP [12], RAPD [13,14], AFLP [15,16], SSR [17] and TRAP [16]. As shown in the different approaches carried out, the employment of molecular markers bring significant improvements to assist in the association of traits with genetic markers and genetic maps, helping in the achievement of significant yield increases in breeding programs [8].

The objective of this study was to establish genetic diversity within a collection of selected sugarcane varieties with important contrasting features under drought conditions, identified in breeding programs in northeastern Brazil, a region that includes extensive semi-arid areas with few agronomic activities. This approach is important to identify contrasting parental candidates for future mapping approaches aiming to identity QTLs associated to drought tolerance/susceptibility and also for the development of comparative expression essays re- garding the same traits.

\section{Material and Methods}

\subsection{Plant Material}

This study evaluated nine sugarcane varieties already cultivated in different countries and widely used in breeding stations located in northeast Brazil. These comprise eight Brazilian sugarcane varieties (SP79-1011, SP701143, SP78-4764, RB98710, RB943365, RB763710, RB75126 and RB863129) from two breeding programs (COPERSUCAR: Sugar and Alcohol Production Syndicate of the São Paulo State, and RIDESA: Inter University Network for Development of Sugar and Alcohol Sector) and one Barbado variety. Plants of SP (COPERSUCAR) and RB (RIDESA) varieties have been maintained by conventional bud propagation in the experimental area of the Carpina Sugarcane Experimental Station (EECAC). All eight SP and RB varieties have important agronomic traits, representing promising material for the development of new cultivars. Additionally, two Indian sugarcane varieties (Co331 and Co419), often cultivated under a wide range of agroclimatic conditions, were employed, representing external contrasting material still not used in Brazilian breeding programs (Table 1).

\subsection{DNA Isolation}

DNA was isolated from young leaf tissues using a CTAB (cetyl-trimethyl-amoniumbromide) protocol [18], with minor modifications [19]. Contaminating polysaccharides were selectively precipitated [20] and DNA concentrations were determined comparatively by electrophoresis

Table 1. Identification of 11 sugarcane varieties used in the ISSR-based genetic diversity assessment, including origin, pedigree and response to drought.

\begin{tabular}{ccccc}
\hline Order & Variety & Origin & Progenitor Accessions & Response to drought \\
\hline 1 & SP79-1011 & COPERSUCAR & NA56-79 $\times$ Co775 & Tolerant \\
2 & SP70-1143 & COPERSUCAR & IAC48-65 $\times$ unknown & Tolerant \\
3 & RB98710 & RIDESA & Unknown & Tolerant \\
4 & RB763710 & RIDESA & F147 $\times$ unknown & Tolerant \\
5 & RB863129 & RIDESA & B73348 $\times$ B74172 & Tolerant \\
6 & B8008 & Barbados & C278 $\times$ unknown & Sensible \\
7 & RB75126 & RIDESA & H66-6254 $\times$ unknown & Sensible \\
8 & SP78-4764 & COPERSUCAR & ROC3 $\times$ RB83100 & Sensible \\
9 & RB943365 & RIDESA & Co213 $\times$ Co214 & Sensible \\
10 & Co331 & SBI, Coimbatore, India & POJ2828 $\times$ Co290 & Unknown \\
11 & Co419 & SBI, Coimbatore, India & Unknown
\end{tabular}

Legend for abbreviations: COPERSUCAR = Sugar and Alcohol Production Syndicate of the state of Sao Paulo, Brazil; RIDESA = Inter University Network for Development of Sugar and Alcohol Sector, Brazil; SBI = Sugarcane Breeding Institute. Genotypes order follow the same arrangement presented in the dendrogram (Figure 1). 
in agarose gel $1.2 \%$ using known amounts of phage $\lambda$ DNA as a reference.

\subsection{ISSR Analysis}

The ISSR amplification reactions contained $15 \eta \mathrm{g}$ of genomic DNA, $2.0 \mu \mathrm{L} 10 \times$ buffer, $2.5 \mathrm{mM} \mathrm{MgCl}_{2}, 200$ $\mu \mathrm{M}$ of each dNTP (Fermentas), $50 \mu \mathrm{M}$ primers and $0.5 \mathrm{U}$ Taq DNA polymerase (Invitrogen), with the final volume adjusted to $20 \mu \mathrm{L}$ with $\mathrm{H}_{2} \mathrm{O}$ bidest. The amplification reaction was carried out in an Eppendorf Mastercycler Gradient or Techn TC-412 thermal cycler. The reaction included an initial denaturation step of 4 min at $94^{\circ} \mathrm{C}$, followed by 30 cycles, each consisting of a denaturation step of $30 \mathrm{~s}$ at $94^{\circ} \mathrm{C}$, annealing of $1 \mathrm{~min}$ at $50.4^{\circ} \mathrm{C}$ to $60.5^{\circ} \mathrm{C}$ (depending on the primer) and an extension of 2 min at $72^{\circ} \mathrm{C}$. PCR was terminated with a final extension of $7 \mathrm{~min}$ at $72^{\circ} \mathrm{C}$. ISSR reaction products were separated on $1.8 \%$ horizontal agarose gels, in TBE buffer with a voltage of $5 \mathrm{~V} / \mathrm{cm}$ and visualized under ultraviolet light after staining in $0.5 \mu \mathrm{g} / \mathrm{mL}$ ethidium bromide. Digital photo documentation was taken for each gel. The $100 \mathrm{bp}$ DNA ladder plus molecular weight marker was used to compare the molecular weight of amplified products. Twelve ISSR primers previously selected for Poaceae species, common cordgrass [21], barley [22] and rice [23] were chosen and ordered from MWG-Biotech for appli- cation on sugarcane varieties (Table 2).

\subsection{Data Analysis}

Polymorphic ISSR markers were scored as binary data: presence (1) or absence (0). Only clearly resolved bands were used in the genetic analysis. The genetic similarity among the varieties was calculated by Jaccard Similarity Coefficient using NTSYS-pc 2.1 software [24]. A dendrogram was constructed based on genetic distance using neighbor-joining method and bootstrap analysis (1000 replicates) with MEGA program (Molecular Evolutionary Genetic Analysis), Version 4 for Windows [25].

\section{Results}

\subsection{PCR Analysis}

The ISSR analysis, carried out in 11 varieties, produced 317 bands, from which 301 (94.9\%) were polymorphic among the sugarcane varieties, with an average of 25 ISSR polymorphic bands per primer. All primers amplified fragments, with a number of amplicons varying from 39 (primer 857) to 14 (primers 807 and 815) fragments per reaction, with sizes varying from $\sim 200 \mathrm{bp}$ to $\sim 2.0 \mathrm{~kb}$ (Table 2). No single band was specific to any individual variety, nor to a given feature. Some primers produced polymorphic bands specific to a set of genotypes (Figure 1).

Table 2. List of ISSR primers used, including their nucleotide sequence, annealing temperature, number of total and polymorphic bands, as well as percentage of polymorphic bands.

\begin{tabular}{|c|c|c|c|c|c|}
\hline Primer & Temp. & 5'-3' Sequence & Total \# bands & \# Polym. bands & $\%$ Polym. \\
\hline UBC 857 & 54.0 & 5'ACACACACACACACACYG3' & 41 & 39 & 90.2 \\
\hline UBC 834 & 52.8 & 5'AGAGAGAGAGAGAGAGYT3' & 37 & 35 & 94.6 \\
\hline UBC 848 & 54.0 & 5'CACACACACACACACARG3' & 37 & 35 & 94.6 \\
\hline UBC 810 & 50.4 & 5'GAGAGAGAGAGAGAGAT3' & 32 & 31 & 96.9 \\
\hline UBC 855 & 52.0 & 5'ACACACACACACACACYT3' & 32 & 30 & 93.7 \\
\hline UBC 811 & 52.8 & 5'GAGAGAGAGAGAGAGAC3' & 27 & 26 & 96.3 \\
\hline UBC 812 & 52.0 & 5'GAGAGAGAGAGAGAGAA3' & 22 & 21 & 95.4 \\
\hline K18 & 54.0 & 5'DVHCACACACACACACA3 & 22 & 21 & 95.4 \\
\hline UBC 828 & 52.8 & 5'TGTGTGTGTGTGTGTGA3' & 18 & 18 & 100 \\
\hline UBC823 & 52.0 & 5'ТСТСТСТСТСТСТСТСС3' & 18 & 17 & 94.4 \\
\hline UBC 807 & 52.0 & 5'AGAGAGAGAGAGAGAGT3' & 16 & 14 & 87.6 \\
\hline UBC 815 & 54.0 & 5'СТСТTCTCTCTCTCTCTG3' & 15 & 14 & 93.3 \\
\hline
\end{tabular}

ISSR primers were obtained from the University of British Colombia (Ayres and Strong 2001, Fernández et al. 2002, Jeung et al. 2005) $\mathrm{R}=(\mathrm{A}, \mathrm{G})$; $\mathrm{Y}=(\mathrm{C}, \mathrm{T})$; $\mathrm{D}=(\mathrm{A}, \mathrm{G}, \mathrm{T})($ i.e. $\operatorname{not} \mathrm{C}) ; \mathrm{H}=(\mathrm{A}, \mathrm{C}, \mathrm{T})($ i.e. not $\mathrm{G}), \mathrm{V}=(\mathrm{A}, \mathrm{C}, \mathrm{G})($ i.e. not $\mathrm{T})$. Legend for abbreviations: Temp. $=$ Annealing temperature; \# = number; Polym. $=$ Polymorphic/Polymorphism. 


\subsection{Clustering Analysis}

The neighbor-joining method generated a dendrogram with two main clusters, where A included two varieties from India (Co331 and Co419) and B comprised one Barbado and eight Brazilian varieties. The drought susceptible accession RB94-3365 occupied a basal position considering the upper branch. The majority of sugarcane varieties clearly grouped into two major clusters in the dendrogram (Figure 2). The first branch included all tolerant varieties divided into two groups. The first group

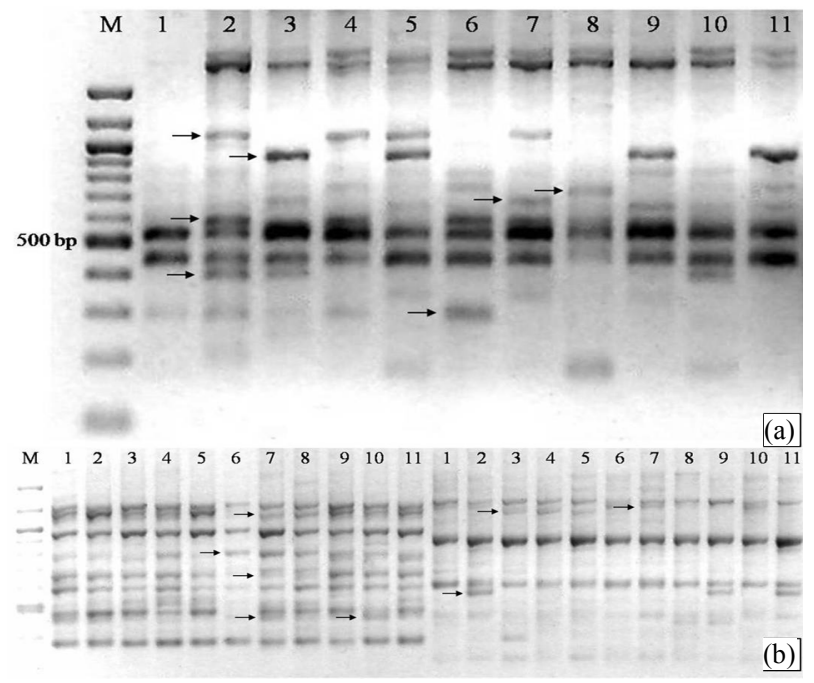

Figure 1. Examples of ISSR amplification results in sugarcane. (a) Amplicons using primer ISSR 815; (b) amplicons using the primers ISSR 810 and 812. M: 100 bp ladder (molecular weight marker). Arrows indicate major polymorphic sites. Order of the genotypes: RB763710, RB863129, SP79-1011, SP70-1143, RB98710, B8008, RB75126, SP784764, RB943365, Co331, Co419.

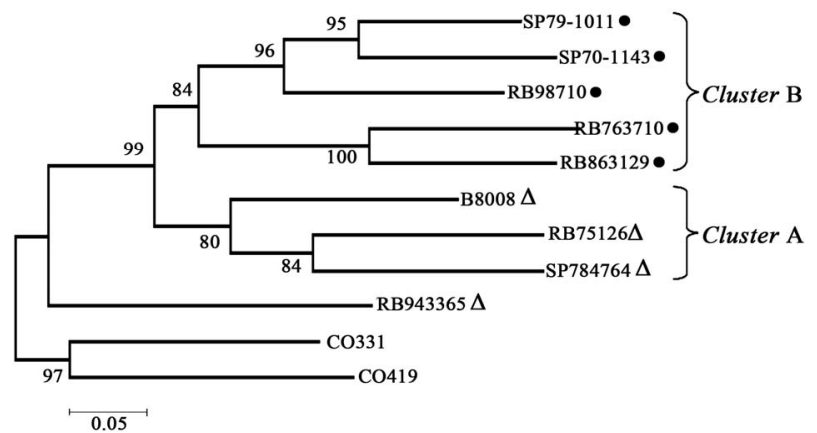

Figure 2. Consensus tree of the analyzed sugarcane accessions based on ISSR data after the Neighbor Joining analysis (complete deletion and $p$-distance) using MEGA program. Bar indicates genetic distance. Bootstrap values $>80$ [1000 replicates] are depicted on the branches. Black circles represent drought tolerant varieties and triangles represent susceptible varieties. comprised two subgroups comprising the varieties SP791011; SP-70-1143; RB98710 and the second one with RB763710; RB863129 varieties. Within this group the accessions RB763710 and RB863129 grouped with high bootstrap value (100). The second branch included all drought susceptible genotypes plus the variety B8008 in a basal position.

Genetic similarity estimates varied from 0.14 (between RB763710 and Co419) to 0.54 (between RB863129 and RB763710) (Table 3). Low coefficients of similarity were detected among sugarcane varieties, with an average similarity value of 0.25 . The lowest similarity coefficient among Brazilian varieties was detected between RB763710 and SP78-4764 (15.8\%), also reflecting their contrasting performance under drought (tolerance and sensitivity to water stress, respectively) (Table 1).

\section{Discussion}

Similar results were reported for other accessions during the evaluation of the genetic diversity of sugarcane varieties with ISSR markers [1] with $78.48 \%$ of the bands produced being polymorphic. However, the result obtained in the present study bear higher polymorphism levels than those previously reported by other authors using RAPD [13,26-28].

The high polymorphism level detected by ISSR markers was expected due to the use of the external Indian varieties and also considering the segmental allopolyploid nature of sugarcane, generally attributed to the interspecific hybridization crosses used during breeding programs that generated the actual breeding accessions. The nature of ISSR, targeting regions especially rich in microsatellites may also justify the higher level of polymorphism, since those regions are known to accumulate a larger number of mutations due to DNA polymerase slippage during replication and unequal crossing-over [29]. Despite of that, researchers who have compared RAPD and ISSR methods have found that ISSR markers exhibit higher level of reproducibility, when compared to RAPD [30-32].

Reduced coefficient of similarity between RB763710 and SP78-4764 varieties of sugarcane has been observed by other authors. Specific regions of the sugarcane genome related to drought tolerance, rather than the entire genome, were sampled to evaluate the genetic variability of candidate parents for breeding purposes [11]. In their study, the lowest similarity value for drought was obtained among the genotypes IACSP95-2078 and SP86-42 (0.44), illustrating that this cross would probably result in the highest variability for drought among the genotypes sampled. The SP86-42 variety presents excellent performance in the Brazilian areas of "Cerrado" vegetation 
Table 3. Similarity matrix among the sugarcane varieties obtained by Jaccard Similarity Coefficient using NTSYS-pc 2.1 software.

\begin{tabular}{|c|c|c|c|c|c|c|}
\hline & RB793710 & RB863129 & SP79-1011 & SP70-1143 & RB98780 & B8008 \\
\hline \multicolumn{7}{|l|}{ RB793710 } \\
\hline RB863129 & 0.5346535 & & & & & \\
\hline SP79-1011 & 0.2586207 & 0.3185841 & & & & \\
\hline SP70-1143 & 0.2338710 & 0.2580645 & 0.5638298 & & & \\
\hline RB98780 & 0.2540984 & 0.2786885 & 0.3738318 & 0.4528302 & & \\
\hline B8008 & 0.2320000 & 0.2868852 & 0.2649573 & 0.3025210 & 0.4090909 & \\
\hline RB75126 & 0.2137405 & 0.2366412 & 0.2338710 & 0.2307692 & 0.2800000 & 0.4907407 \\
\hline SP78-4764 & 0.1587302 & 0.2016129 & 0.2173913 & 0.1951220 & 0.1951220 & 0.3097345 \\
\hline RB943365 & 0.1666667 & 0.1984733 & 0.2032520 & 0.1923077 & 0.2204724 & 0.2187500 \\
\hline Co331 & 0.1600000 & 0.1472868 & 0.1680672 & 0.1869919 & 0.1680000 & 0.1854839 \\
\hline \multirow[t]{2}{*}{ Co419 } & 0.1451613 & 0.1600000 & 0.1826087 & 0.1532258 & 0.1532258 & 0.1520000 \\
\hline & RB75126 & SP78-4764 & RB943365 & Co331 & Co419 & \\
\hline \multicolumn{7}{|l|}{ RB793710 } \\
\hline \multicolumn{7}{|l|}{ RB863129 } \\
\hline \multicolumn{7}{|l|}{ SP79-1011 } \\
\hline \multicolumn{7}{|l|}{ SP70-1143 } \\
\hline \multicolumn{7}{|l|}{ RB98780 } \\
\hline \multicolumn{7}{|l|}{ B8008 } \\
\hline \multicolumn{7}{|l|}{ RB75126 } \\
\hline SP78-4764 & 0.5000000 & & & & & \\
\hline RB943365 & 0.2578125 & 0.3333333 & & & & \\
\hline Co331 & 0.1692308 & 0.1880342 & 0.4000000 & & & \\
\hline Co419 & 0.1640625 & 0.1826087 & 0.3090909 & 0.4062500 & & \\
\hline
\end{tabular}

(fire adapted savannas characterized by poor and mineralized soils), being also grown in drought-prone environments.

Data analysis using the neighbor-joining method generated a dendrogram with two main clusters that grouped individuals that share the same gene pool of origin. Cluster "A" included two varieties whose genomic background is mainly from plants used in breeding programs from India (Co331 and Co419), and cluster "B" included eight Brazilian varieties and one Barbado variety. All accessions included in this last cluster have been used as parental in crosses carried out in Brazilian breeding programs aiming to generate drought tolerant material.

The accession RB94-3365 is the genetic basis of all analyzed Brazilian varieties, due to its high productivity, despite of drought susceptibility, justifying its basal position considering the upper branch. The majority of sugarcane varieties clearly grouped into two major clusters in the dendrogram with a bootstrap of 99 . Within this group, the first branch emerged with bootstrap 84, including all tolerant varieties divided into two groups.
The first group within the upper cluster included two subgroups, one comprising three (SP79-1011; SP-70-1143; RB98710) and the second with two (RB763710; RB863129) accessions. Within this branch, RB763710 and RB863129 grouped with a bootstrap of 100. Besides being tolerant to drought, both varieties (RB763710 and SP79-1011) are sources of resistance against rust and present contrasting maturation time, growth habit and sugar yield potentials, being very useful candidates in future breeding programs.

The second branch within the upper cluster presented bootstrap 80 and included all drought susceptible genotypes, with the Barbado variety (B8008) in a basal position, a material identified as source of resistance against rust and bearing high sugar production.

Differential responses to abiotic stress were observed among clusters. The association of drought-tolerance present in RB varieties (RB863129, RB763710 and RB98710) and SP varieties (SP70-1143 and SP79-1011) in the same branch, was supported by high bootstrap scores (84), indicating that these accessions are also in- 
teresting for breeding of this feature [33,34]. Considering salinity sensitive varieties, two groups had been formed: the first containing one variety (RB943365) and the second with three varieties (SP78-4764, RB75126 and B8008). This is promising, especially considering that other authors have shown that the genetic variations identified with aid of molecular markers are useful in evaluating upland accessions for drought-tolerance with related morphology [35].

The same was observed regarding sugarcane genotypes with contrasting response to red rot disease [36]. The authors reported the usefulness of ISSR markers to separate red-rot disease resistant, moderately resistant and susceptible among sugarcane genotypes. The sugarcane accessions Co 8011, Co 86010, Co 85061, Co 62198, Co 86032, GSBT 9 and Co 8014 that are resistant to moderately resistant to red rot disease were grouped into one cluster, while remaining genotypes Co 7804, Co 62175 , Co 8371 and Co 671, susceptible to red rot disease, were grouped into another cluster.

Several authors have reported high genetic similarity among sugarcane varieties using RAPD [13,14,27]. This genetic homogeneity, in spite of regional adaptation and selection history, is probable due to the repeated use of few sets of nearly related varieties. In addition, considering the supposed narrow genetic basis of sugarcane varieties based on RAPD markers, one may suppose that other techniques have to be tested in the search for more efficient polymorphism identification. For example, using AFLP to analyze commercial sugarcane varieties grown under tropical and subtropical regions of India the level of genetic diversity among the tropical and subtropical cultivars was much higher than most of the pairwise diversity measures within each of these two adaptive groups. The AFLP-based clustering of the cultivars also corresponded well with their known pedigree [37]. This method is really more effective than RAPD, but presents the disadvantage of being more expensive and time consuming than ISSR.

The results obtained here using ISSR were comparable to other studies with Poaceae. In a study using AFLP and ISSR molecular markers to evaluate the genetic diversity and relationships of 56 waxy rice accessions, a single ISSR primer $\mathrm{BDB}(\mathrm{AC})_{7}$ produced a total of 88 bands ranging from 200 to $600 \mathrm{bp}$, including 77 polymorphic bands [38]. The average polymorphism of the total ISSR markers was $92.2 \%$, much higher than that observed for AFLP.

Similarly, authors reported the usefulness of ISSR in surveying genetic variation of 46 barley accessions [32]. For this purpose, 18 primers were used, generating a total of 107 bands with 105 (98.13\%) polymorphic bands, with two to 10 polymorphic bands per primer.

The present results revealed considerable levels of genetic diversity to design crosses for mapping purposes employing linkage analysis aiming to identify QTLs with aid of DNA markers considering the analyzed varieties. Moreover, unambiguous discrimination and identification of cultivars using ISSR markers are of significance in the context of establishing clone fidelity, cultivar certification and germplasm management.

The here tested ISSR primers were tested for the first time in sugarcane and presented better performance regarding the detection of polymorphisms in this crop, than previously used ISSR primers. Especially considering the narrow genetic basis of many existing genetic banks in sugarcane, they represent additional possibilities for diversity screening. In the case of the present evaluation they helped in the planning of futures crosses using drought tolerant varieties with the most productive drought sensible cultivars, aiming the direct breeding of this important feature, as well as for the identification of most contrasting drought tolerant and sensible materials for a cross aiming the construction of a genetic map for QTL identification.

\section{Acknowledgements}

To CNPq (Conselho Nacional de Desenvolvimento Científico e Tecnológico, Brazil) for fellowships and research support. For the concession of varieties we thank the RIDESA (Rede Interuniversitária para o Desenvolvimento do Setor Sucroalcooleiro, Brazil) through the EECAC (Estação Experimental de Cana-de-Açúcar do Carpina, Brazil).

\section{REFERENCES}

[1] S. Srivastava and O. S. Gupta, "Inter Simple Sequence Repeat Profile as a Genetic Marker System in Sugarcane," Sugar Tech, Vol. 10, No. 1, 2008, pp. 48-52. doi:10.1007/s12355-008-0008-y

[2] D. W. Cornland, F. X. Johnson, F. Yamba, E. N. Chidumayo, M. M. Morales, O. Kalumiana and S. B. MtongaChidumayo, "Sugarcane Resources for Sustainable Development: A Case Study in Luena, Zambia," Stockholm Environment Institute, Stockholm, 2001.

[3] K. S. Aitken, J. C. Li, P. Jackson, G. Piperidis and C. L. MCintyre, "AFLP Analysis of Genetic Diversity within Saccharum officinarum and Comparison with Sugarcane Cultivars," Australian Journal of Agricultural Research, Vol. 57, No. 11, 2006, pp. 1167-1184. doi:10.1071/AR05391

[4] F. C. Atkin, M. J. Dieters and J. K. Stringer, "Impact of Depth of Pedigree and Inclusion of Historical Data on the Estimation of Additive Variance and Breeding Values in a Sugarcane Breeding Program," Theoretical and Applied 
Genetics, Vol. 119, No. 3, 2009, pp. 555-565. doi:10.1007/s00122-009-1065-7

[5] A. D'Hont, P. S. Rao, P. Feldmann, L. Grivet, F. N. Islam, P. Taylor and J. C. Glaszmann, "Identification and Characterisation of Sugarcane Intergeneric Hybrids, Saccharum officinarum $\times$ Erianthus arundinaceus, with Molecular Markers and DNA in Situ Hybridisation," Theoretical and Applied Genetics, Vol. 91, No. 2, 1995, pp. 320-326. doi:10.1007/BF00220894

[6] P. C. Bundock, F. G. Eliott, G. Ablett, A. D. Benson, R. E. Casu, K. S. Aitken and R. J. Henry, "Targeted Single Nucleotide Polymorphism (SNP) Discovery in a Highly Polyploid Plant Species Using 454 Sequencing," Plant Biotechnology Journal, Vol. 7, No. 4, 2009, pp. 347-354. doi:10.1111/j.1467-7652.2009.00401.x

[7] S. K. Parida, K. K. Sanjay, K. Sunita, V. Dalal, G. Hemaprabha, A. Selvi, A. Pandit, A. Singh, K. Gaikwad, T. R. Sharma, P. S. Srivastava, N. K. Singh and T. Mohapatra, "Informative Genomic Microsatellite Markers for Efficient Genotyping Applications in Sugarcane," Theoretical and Applied Genetics, Vol. 118, No. 2, 2009, pp. 327-338. doi:10.1007/s00122-008-0902-4

[8] S. L. Dillon, F. M. Shapter, R. J. Henry, G. Cordeiro, L. Izquierdo and S. L. Lee, "Domestication to Crop Improvement: Genetic Resources for Sorghum and Saccharum (Andropogoneae)," Annals of Botany, Vol. 100, No. 5, 2007, pp. 975-989. doi:10.1093/aob/mcm192

[9] L. M. Raboin, J. Pauquet, M. Butterfield, A. D'Hont and J. C. Glaszmann, "Analysis of Genome-Wide Linkage Disequilibrium in the Highly Polyploid Sugarcane," Theoretical and Applied Genetics, Vol. 116, No. 5, 2008, pp. 701-714. doi:10.1007/s00122-007-0703-1

[10] K. M. Oliveira, L. R. Pinto, T. G. Marconi, M. Mollinari, E. C. Ulian, S. M. Chabregas, M. C. Falco, W. Burnquist, A. A. F. Garcia and A. P. Souza, "Characterization of New Polymorphic Functional Markers for Sugarcane," Genome, Vol. 52, No. 2, 2009, pp. 191-209. doi: $10.1139 / \mathrm{G} 08-105$

[11] S. Creste, K. A. G. Accoroni, L. R. Pinto, R. Vencovsky, M. A. Gimenes, M. A. Xavier and M. G. A. Landell, "Genetic Variability among Sugarcane Genotypes Based on Polymorphisms in Sucrose Metabolism and Drought Tolerance Genes," Euphytica, Vol. 172, No. 3, 2010, pp. 435-446. doi:10.1007/s10681-009-0078-2

[12] N. Jannoo, L. Grivet, M. Seguin, F. Paulet, R. Domaingue, P. S. Rao, A. Dookun, A. D'Hont and J. C. Glaszmann, "Molecular Investigation of the Genetic Base of Sugarcane Cultivars," Theoretical and Applied Genetics, Vol. 99 , No. 1, 1999, pp. 171-184. doi:10.1007/s001220051222

[13] P. G. Kawar, R. M. Devarumath and Y. Nerkar, "Use of RAPD Markers for Assessment of Genetic Diversity in Sugarcane Cutivars," Indian Journal of Biotechnology, Vol. 8, No. 1, 2009, pp. 67-71.

[14] F. A. Khan, A. Khan, F. M. Azhar and S. Rauf, "Genetic Diversity of Saccharum officinarum Accessions in Pakistan as Revealed by Random Amplified Polymorphic
DNA," Genetics and Molecular Research, Vol. 8, No. 4, 2009, pp. 1376-1382. doi:10.4238/vol8-4gmr665

[15] M. L. Lima, A. A. Garcia, K. M. Oliveira, S. Matsuoka, H. Arizono, C. L. De Souza Jr. and A. P. De Souza, "Analysis of Genetic Similarity Detected by AFLP and Coefficient of Parentage among Genotypes of Sugar Cane (Saccharum spp.)," Theoretical and Applied Genetics, Vol. 104, No. 1, 2002, pp. 30-38. doi: $10.1007 / \mathrm{s} 001220200003$

[16] S. Alwala, C. A. Kimbeng, K. A. Gravois and K. P. Bischoff, "Trap a New Tool for Sugarcane Breeding: Comparison with AFLP and Coefficient of Parentage," Journal American Society of Sugar Cane Technologists, Vol. 26, No. 1, 2006, pp. 62-87.

[17] N. C. Glynn, K. Mccorkl and J. C. Comstock, "Diversity among Mainland USA Sugarcane Cultivars Examined by SSR Genotyping," Journal American Society of Sugar Cane Technologists, Vol. 29, No. 1, 2009, pp. 36-52.

[18] K. Weising, H. Nybom, K. Wolff and W. Meyer, "DNA Fingerprinting in Plants and Fungi," CRC Press Inc., Boca Raton, 1995.

[19] A. M. Benko-Iseppon, P. Winter, B. Hüttel, F. J. Muehlbauer, C. Stagginus and G. Kahl, "Pathogen-Related Sequences around Fusarium Race 4 Resistance Locus in Chickpea Detected by DNA Amplification Fingerprinting (DAF)," Theoretical and Applied Genetics, Vol. 107, No. 2, 2003, pp. 379-386. doi:10.1007/s00122-003-1260-x

[20] S. D. Michaels, M. C. John and R. M. Amasino, "Removal of Polysaccharides from Plant DNA by Ethanol Precipitation," Biotechniques, Vol. 17, No. 2, 1994, pp. 274-276.

[21] D. R. Ayres and D. R. Strong, "Origin and Genetic Diversity of Spartina anglica (Poaceae) Using Nuclear DNA Markers," American Journal of Botany, Vol. 88, No. 10, 2001, pp. 1863-1867. doi:10.2307/3558362

[22] M. E. Fernández, A. M. Figueiras and C. Benito, "The Use of ISSR and RAPD Markers for Detecting DNA Polymorphism, Genotype Identification and Genetic Diversity among Barley Cultivars with Known Origin," Theoretical and Applied Genetics, Vol. 104, No. 5, 2002, pp. 845-851. doi:10.1007/s00122-001-0848-2

[23] J. U. Jeung, H. G. Hwang, H. P. Moon and K. K. Jena, "Fingerprinting Temperate Japonica and Tropical Indica Genotypes by Comparative Analysis of DNA Markers," Euphytica, Vol. 146, No. 3, 2005, pp. 239-251. doi:10.1007/s10681-005-9022-2

[24] F. J. Rohlf, "NTSYS-pc: Numerical Taxonomy and Multivariate Analysis System, Version 2.1," Exeter Software, 2000.

[25] S. Kumar, K. Tamura and M. Nei, "MEGA 3: Integrated Software for Molecular Evolutionary Genetics Analysis and sequence Alignment, Version 3.1," Briefings in Bioinformatics, Vol. 5, No. 2, 2004, pp. 150-163. doi:10.1093/bib/5.2.150

[26] D. M. Burner, Y. B. Pan and R. D. Webster, "Genetic Diversity of North American and Old World Saccharum 
Assessed by RAPD Analysis," Genetic Resources and Crop Evolution, Vol. 44, No. 3, 1997, pp. 235-240. doi:10.1023/A:1008631731506

[27] N. V. Nair, A. Selvi, T. V. Sreenivasan and K. N. Pushpalatha, "Molecular Diversity in Indian Sugarcane Cultivars as Revealed by Randomly Amplified DNA Polymorphisms," Euphytica, Vol. 127, No. 2, 2002, pp. 219-225. doi:10.1023/A:1020234428681

[28] C. M. Da Silva, C. A. Mangolin, A. S. Mott and M. F. P. S. Machado, "Genetic Diversity Associated with in Vitro and Conventional Bud Propagation of Saccharum Varieties Using RAPD Analysis," Plant Breeding, Vol. 127, No. 2, 2008, pp. 160-165. doi:10.1111/j.1439-0523.2007.01438.x

[29] C. Schlötterer and D. Tautz, "Slippage Synthesis of Simple Sequence DNA," Nucleic Acids Research, Vol. 20, No. 2, 1992, pp. 211-215. doi:10.1093/nar/20.2.211

[30] L. Goulão and C. M. Oliveira, "Molecular Characterization of Cultivars of Apple (Malus $\times$ domestica Borkh.) Using Microsatellite (SSR and ISSR) Markers," Euphytica, Vol. 122, No. 1, 2001, pp. 81-89. doi:10.1023/A:1012691814643

[31] W. Qian, S. Ge and D. Y. Hong, "Genetic Variation within and among Populations of Wild Rice Oryza granulate from China Detected by RAPD and ISSR Markers," Theoretical and Applied Genetics, Vol. 102, No. 2-3, 2001, pp. 440-449. doi:10.1007/s001220051665

[32] Y. C. Hou, Z. H. Yan, Y. M. Wei and Y. L. Zheng, "Genetic Diversity in Barley from West China Based on RAPD and ISSR Analysis," Barley Genetics Newsletter, Vol. 35, No. 1, 2005, pp. 9-22.
[33] R. R. Gomes-Filho and J. F. Tahin, "Respostas Fisiológicas de Cultivares de Caupi (Vigna unguiculata L.) Eretos e Decumbentes a Diferentes Níveis de Irrigação," Engenharia Agrícola, Vol. 10, No. 1, 2002, pp. 56-60.

[34] C. Pimentel, B. Sarr, O. Diouf, A. C. Z. Abboud and H. Roy-Macauley, "Tolerância Protoplasmática Foliar à Seca, em Dois Genótipos de Caupi Cultivados em Campo," Revista Universidade Rural, Vol. 22, No. 1, 2002, pp. 7-14.

[35] L. Zeng, T. R. Kwon, X. Liu, C. Wilson, C. M. Grieve and G. B. Gregorio, "Genetic Diversity Analyzed by Microsatellite Markers among Rice Genotypes with Different Adaptations to Saline Soils," Plant Science, Vol. 166 No. 5, 2004, pp. 1275-1285. doi:10.1016/j.plantsci.2004.01.005

[36] S. Virupakshi and G. R. Naik, "ISSR Analysis of Chloroplast and Mitochondrial Genome Can Indicate the Diversity in Sugarcane Genotypes for Red Rot Resistance,' Sugar Tech, Vol. 10, No. 1, 2008, pp. 65-70. doi:10.1007/s12355-008-0011-3

[37] A. Selvi, N. V. Nair, J. L. Noyer, N. K. Singh, K. C. Balasundaram, K. C. Bansal, K. R. Koundal and T. Mohapatra, "Genomic Constitution and Genetic Relationship among the Tropical and Subropical Indian Sugarcane Cultivars Revealed by AFLP," Crop Science, Vol. 45, No. 5, 2005, pp. 1750-1757. doi:10.2135/cropsci2004.0528

[38] J. Bao, H. Corke and M. Sun, "Analysis of Genetic Diversity and Relationships in Waxy Rice (Oryza sativa L.) Using AFLP and ISSR Markers," Genetic Resources and Crop Evolution, Vol. 53, No. 2, 2006, pp. 323-330. doi:10.1007/s10722-004-6145-6 